\title{
A NOTE ON OPTIMAL INCOME REDISTRIBUTION IN A CREATIVE REGION $^{1}$
}

\author{
Amitrajeet A. BATABYAL \\ Department of Economics, Rochester Institute of Technology, 92 Lomb Memorial Drive, Rochester, \\ NY 14623-5604, USA. \\ aabgsh@rit.edu
}

\begin{abstract}
We study optimal income redistribution in a region that is creative in the sense of Richard Florida and thereby extend aspects of the recent analysis in Batabyal and Beladi (2017). Using the terminology of these researchers, members of the creative class are either artists or engineers. This bipartite grouping stems from the manner in which creative capital is acquired by the artists and the engineers. Specifically, we show that when the savings rates of the artists and the engineers comprising the creative class satisfy a particular inequality, it is possible for a regional authority (RA) to uniquely redistribute income between these two groups in a way that achieves the so called "golden rule" stock of physical capital.
\end{abstract}

Keywords: Creative Capital, Creative Class, Golden Rule, Income Redistribution, Region JEL classification: R11, D31

\section{Introduction}

According to the urbanist Richard Florida (2002, p. 68), the creative class "consists of people who add economic value through their creativity." This class consists of professionals such as doctors, lawyers, scientists, engineers, university professors, and, notably, bohemians such as artists, musicians, and sculptors. The distinguishing feature of these people is that they possess creative capital which is defined to be the "intrinsically human ability to create new ideas, new technologies, new business models, new cultural forms, and whole new industries that really [matter]" (Florida, 2005, p. 32).

With these twin definitions of the creative class and creative capital in place, we can ask the following question: Is there any difference between the well-known notion of human capital and Florida's newer concept of creative capital? To answer this question, first note that in empirical research, the concept of human capital is typically measured with education or with education based indicators. This notwithstanding, Marlet and Van Woerkens (2007) have rightly argued that the accumulation of creative capital does not always depend on the acquisition of a formal education. Put differently, while the creative capital accumulated by some members of Florida's creative class (doctors, engineers, university professors) does depend on the completion of many years of formal education, the same is not always true of other members of this creative class (artists, painters, poets). Individuals in this latter group may be innately creative and hence possess creative capital despite having very little or no formal education.

Therefore, we are in agreement with Marlet and Van Woerkens (2007) and we would like to emphasize the point that there is little or no difference between the concepts of human and creative capital when the accumulation of this creative capital depends on the completion of many years of formal education. In contrast, there can be a lot of difference between the concepts of human and creative capital when the accumulation of this creative capital does not have to depend on the completion of a formal education. Simply put, because creative capital is of two types, it is a more general concept than the notion of human capital.

\footnotetext{
1 Batabyal acknowledges financial support from the Gosnell endowment at RIT. The usual disclaimer applies.
} 
In a recent paper, Batabyal and Beladi (2017) point out that although there exist many empirical or case study based analyses of the creative class and the impact that this class has on regional economic growth, there are no theoretical studies of the creative class that explicitly model the idea that the creative capital possessed by the members of a region's creative class is of two possible types. As such, they provide the first theoretical analysis of economic growth in a region that is creative in the sense of Richard Florida and where members of the creative class belong to one of two possible groups.

A key contribution of Batabyal and Beladi (2017) lies in its explicit analysis of income distribution issues within the creative class in the region under study. In this regard, two results from the paper are germane. First, the paper shows that when the savings rates of the two groups that comprise the creative class are identical, the distribution of income in the creative region has no effect on the steady state physical capital per creative class member ratio. Second, the paper determines the optimal income redistribution rule that maximizes the average steady state income of the creative class.

In this note we extend aspects of the analysis in Batabyal and Beladi (2017). Specifically, we show that when the savings rates of the two groups that comprise the creative class satisfy a particular inequality, it is possible for a regional authority (RA) to uniquely redistribute income between these two groups in a way that achieves the so called "golden rule" stock of physical capital. The remainder of this note is organized as follows. Section 2 delineates the Batabyal and Beladi (2017) theoretical framework that we work with here. Section 3 shows that there exists a unique income redistribution rule that achieves the "golden rule" stock of physical capital. Section 4 concludes and then suggests two ways in which the research described in this note might be extended.

\section{The Theoretical Framework}

Consider an intertemporal regional economy that is creative in the sense of Richard Florida. Time is discrete. Let $N_{t}$ denote the number of persons at time $t$ who comprise the creative class in this region. There are two groups of persons. The first group refers to members of the creative class who are innately creative and hence possess creative capital with little or no formal schooling. These are the artists. At any time $t$, the total number of artists in our creative region is $N_{t}^{A}$. The second group refers to the creative class members who are creative as a result of the acquisition of creative capital through many years of education. These are the engineers. Let $N_{t}^{E}$ denote the total number of engineers at time $t$ in our creative region. Note that the relationship

$$
N_{t}=N_{t}^{A}+N_{t}^{E}, \forall t_{p}
$$

holds in our creative region.

Each member of the creative class inelastically supplies one unit of effort. Hence, at any time $t$, every artist receives a wage (unit income) denoted by $w_{t}^{A}$ and every engineer receives a wage denoted by $w_{t}^{E}$. Using these two pieces of information and equation (1), we can write

$$
N_{t} w_{t}=N_{t}^{A} w_{t}^{A}+N_{t}^{E} w_{t}^{E}, \forall t_{t}
$$

for the aggregate economy of our creative region. We denote the wage (unit income) ratio in our creative region by $w_{t}^{A} / w_{t}^{E}=\phi$ where $\phi \in(0, \infty)$. It is important to comprehend that $\phi$ is the income distribution parameter in this note. Obviously, when $\phi=1$, the incomes of the two groups are equal. However, $\phi \in(0, \infty)$. Therefore, to the right of the point $\phi=1$, as $\phi \rightarrow \infty$ we have inequality of one kind because the income of artists becomes much larger than the income of engineers. In contrast, to the left of the point $\phi=1$, as $\phi \rightarrow 0$ we have inequality of a second kind in that the income of artists becomes much smaller than the income of engineers. Finally, the proportion of artists in the creative class population is $\zeta \in(0,1)$ and hence the proportion of engineers in this same population is $(1-\zeta)$. The creative class population grows at the constant rate $c>0$.

The members of the creative class collectively produce a knowledge good such as a laptop computer that is also the final consumption good. The price of this knowledge good is 
set equal to one at all points in time. The output of this knowledge good per creative class member at time $t$ is $q_{t}=Q_{t} / N_{t}$ and this output is generated by a Cobb-Douglas production function which, in its intensive form, can be written as

$$
q_{t}=f\left(k_{z}\right)=k_{t}^{\alpha}
$$

where $\alpha \in(0,1)$ and $k_{t}=K_{t} / N_{t}$ is the physical capital per creative class member ratio. There are constant returns to scale in production and we assume that the equilibrium wage and the interest rate $\left(\boldsymbol{r}_{\boldsymbol{t}}\right)$ are set equal to the respective marginal productivities.

The savings rates of the artists and engineers are constants denoted by $\lambda^{A} \in(0,1)$ and $\lambda^{z} \in(0,1)$ respectively. For most of their paper, Batabyal and Beladi (2017) suppose that artists save less then engineers and hence these two savings rates satisfy

$$
0<\lambda^{A}<\lambda^{E}<1 \text {. }
$$

It is this inequality in (4) that we alter in our subsequent analysis in this note. However, before we can get to this analysis, it will be necessary to state a particular result obtained by Batabyal and Beladi (2017). Specifically, these researchers show that the steady state physical capital per creative class member ratio or $k^{S S}$ is given by

$$
k^{S S}=\left\{\frac{\lambda(1-\alpha)}{1+e}\right\}^{1 /(1-\alpha)}
$$

where $\lambda$ satisfies

$$
\lambda=\frac{\phi \zeta \lambda^{A}+(1-\zeta) \lambda^{I}}{\phi \zeta+(1-\zeta)}
$$

We are now in a position to demonstrate that there exists a unique income redistribution rule that achieves the "golden rule" stock of physical capital.

\section{The Unique Income Redistribution Rule}

Let us begin by denoting the unique income distribution rule that we seek by $\phi^{V}$. Next, let $k^{G R}$ denote the "golden rule" stock of physical capital. Two points about $k^{G R}$ are now worth emphasizing. First, adapting the notion of a golden rule stock of physical capital from standard economic growth theory ${ }^{2}$ to our creative region, we would say that $k^{G \pi}$ is the physical capital per creative class member ratio that maximizes consumption per creative class member in the region under study. Second and once again adapting from standard economic growth theory, the golden rule stock of physical capital is given by

$$
f^{\prime}(k)=c \text {. }
$$

In light of equation (7), let us differentiate the production function in equation (3). We get $\alpha k^{\alpha-1}=c$. This last expression can be simplified to give

$$
k^{G R}=\left(\frac{a}{\sigma}\right)^{1 /(1-\alpha)}
$$


The next step is to set the steady state physical capital per creative class member ratio equal to the golden rule stock of physical capital. In other words, we want to set $k^{S S}=k^{G R}$ in equation (5). This gives us

$$
\left(\frac{\alpha}{\sigma}\right)^{1 /(1-\alpha)}=\left\{\frac{\lambda(1-\alpha)}{1+e}\right\}^{1 /(1-\alpha)}
$$

Equation (9) can be simplified to give us an equation for $\lambda$. That equation is

$$
\lambda=\frac{\alpha(1+\sigma)}{\sigma(1-\alpha)}
$$

Finally, using equation (10) and the definition of $\lambda$ given in equation (6), we can solve explicitly for the unique income redistribution rule $\phi^{U}$. We get

$$
\phi^{U}=\left(\frac{1-\zeta}{\zeta}\right)\left\{\frac{\lambda^{E}-\frac{a(1+\varepsilon)}{\sigma(1-\alpha)}}{\frac{\alpha(1+\Sigma)}{[(1-\alpha)}-\lambda^{A}}\right\}
$$

Inspecting equation (11), it should be clear to the reader that $\phi^{U}$ is unique because it is a well-defined function of unique constants. In addition, the ratio $(1-\zeta) / \zeta$ on the right-handside (RHS) of equation (11) is positive. Therefore, the product of the two ratios on the RHS of equation (11) and hence $\phi^{U}$ will be positive as long as for $\lambda^{A}<\lambda^{E}$, we have

$$
\lambda^{E}-\frac{a(1+c)}{\sigma(1-\alpha)}>0
$$

$$
\begin{aligned}
& \text { and } \\
& \frac{\alpha(1+o)}{a(1-\alpha)}-\lambda^{A}>0 .
\end{aligned}
$$

Combining the inequalities in (12) and (13), we see that the unique income redistribution rule given by $\phi^{V}$ is positive as long as the following inequality

$$
0<\lambda^{A}<\left(\frac{\alpha}{1-\alpha}\right)\left(\frac{1+c}{\sigma}\right)<\lambda^{E}<1
$$

holds. We have just demonstrated that as long as the inequality in (14) holds, the RA in our creative region will be able to use the unique income redistribution rule $\phi^{U}$ to redistribute income in a way that achieves the "golden rule" stock of physical capital. This completes our discussion of optimal income redistribution in a creative region.

\section{The Unique Income Redistribution Rule}

Let us begin by denoting the unique income distribution rule that we seek by $\phi^{U}$. Next, let $k^{G R}$ denote the "golden rule" stock of physical capital. Two points about $k^{G R}$ are now worth emphasizing. First, adapting the notion of a golden rule stock of physical capital from standard economic growth theory ${ }^{3}$ to our creative region, we would say that $k^{G R}$ is the

\footnotetext{
${ }^{3}$ See Acemoglu (2009, pp. 42-43) for additional details on the golden rule physical capital stock.
} 
physical capital per creative class member ratio that maximizes consumption per creative class member in the region under study. Second and once again adapting from standard economic growth theory, the golden rule stock of physical capital is given by

$$
f^{\prime}(k)=c \text {. }
$$

In light of equation (7), let us differentiate the production function in equation (3). We get $\alpha k^{\alpha-1}=c$. This last expression can be simplified to give

$$
k^{C R}=\left(\frac{a}{\sigma}\right)^{1 /(1-\alpha)}
$$

The next step is to set the steady state physical capital per creative class member ratio equal to the golden rule stock of physical capital. In other words, we want to set $k^{S S}=k^{G E}$ in equation (5). This gives us

$$
\left(\frac{\alpha}{\sigma}\right)^{1 /(1-\alpha)}=\left\{\frac{\lambda(1-\alpha)}{1+\sigma}\right\}^{1 /(1-\alpha)}
$$

Equation (9) can be simplified to give us an equation for $\lambda$. That equation is

$$
\lambda=\frac{\alpha(1+c)}{\sigma(1-\alpha)}
$$

Finally, using equation (10) and the definition of $\lambda$ given in equation (6), we can solve explicitly for the unique income redistribution rule $\phi^{U}$, We get

$$
\phi^{V}=\left(\frac{1-\zeta}{\zeta}\right)\left\{\frac{\lambda^{E}-\frac{\alpha(1+\sigma)}{\sigma(1-w)}}{\frac{a(1+\sigma)}{\Sigma(1-\alpha)}-\lambda^{A}}\right\} .
$$

Inspecting equation (11), it should be clear to the reader that $\phi^{U}$ is unique because it is a well-defined function of unique constants. In addition, the ratio $(1-\zeta) / \zeta$ on the right-handside (RHS) of equation (11) is positive. Therefore, the product of the two ratios on the RHS of equation (11) and hence $\phi^{U}$ will be positive as long as for $\lambda^{A}<\lambda^{E}$, we have

$$
\lambda^{E}-\frac{\alpha(1+c)}{c(1-\alpha)}>0
$$

and

$$
\frac{\alpha(1+c)}{c(1-\alpha)}-\lambda^{A}>0
$$

Combining the inequalities in (12) and (13), we see that the unique income redistribution rule given by $\phi^{U}$ is positive as long as the following inequality

$$
0<\lambda^{A}<\left(\frac{\alpha}{1-\alpha}\right)\left(\frac{1+\sigma}{\sigma}\right)<\lambda^{E}<1
$$

holds. We have just demonstrated that as long as the inequality in (14) holds, the RA in our creative region will be able to use the unique income redistribution rule $\phi^{V}$ to redistribute income in a way that achieves the "golden rule" stock of physical capital. This completes our discussion of optimal income redistribution in a creative region. 


\section{Conclusions}

In this note we studied optimal income redistribution in a region that was creative in the sense of Richard Florida and thereby extended parts of the analysis in Batabyal and Beladi (2017). Using the language of these researchers, members of the creative class were either artists or engineers. This bipartite grouping stemmed from the manner in which creative capital was acquired by the artists and the engineers. Specifically, we showed that when the savings rates of the artists and the engineers comprising the creative class satisfied a particular inequality, it was possible for a regional authority (RA) to uniquely redistribute income between these two groups in a way that achieved the "golden rule" stock of physical capital.

The analysis in this note can be extended in a number of different directions. In what follows, we suggest two possible extensions. First, it would be useful to extend the analysis conducted here by considering the case in which one group (artists or engineers) produce an intermediate good which is then used by the other group to produce the final consumption good. Second, it would also be informative to embed the economy of the creative region analyzed here in a stochastic environment and then analyze the impact that uncertainty about the actual savings rates of either artists and/or engineers has on the functioning of the regional economy under study. Studies that analyze these aspects of the underlying problem will provide additional insights into the nexuses between the activities of artists and engineers in a creative region and aggregate economic performance in this same region.

\section{References}

1. Acemoglu, D. 2009. Introduction to Modern Economic Growth. Princeton University Press, Princeton, NJ.

2. Batabyal, A.A., and Beladi, H. 2017. Artists, Engineers, and Aspects of Economic Growth in a Creative Region, Munich Personal RePEc Archive (MPRA) Paper No. 79573.

3. Florida, R. 2002. The Rise of the Creative Class. Basic Books, New York, NY.

4. Florida, R. 2005. The Flight of the Creative Class. Harper Business, New York, NY.

5. Marlet, G., and Van Woerkens, C. 2007. The Dutch creative class and how it fosters urban employment growth, Urban Studies, 44, 608-630. 